\title{
HMG-CoA reductase inhibition aborts functional differentiation and triggers apoptosis in cultured primary human monocytes: a potential mechanism of statin-mediated vasculoprotection Joannis E Vamvakopoulos*1,3 and Colin Green ${ }^{2}$
}

Address: ${ }^{1}$ Department of Surgery, University of Cambridge, Cambridge, UK, ${ }^{2}$ Northwick Park Institute for Medical Research, Harrow, UK and ${ }^{3}$ Current address: Rational Drug Design Program, Biomedicum Helsinki, Helsinki, Finland

Email: Joannis E Vamvakopoulos* - joannis@scientist.com; Colin Green - s.jenks@ic.ac.uk

* Corresponding author

Published: 19 July 2003

BMC Cardiovascular Disorders 2003, 3:6
Received: 26 February 2003

Accepted: 19 July 2003

This article is available from: http://www.biomedcentral.com//47I-226I/3/6

(C) 2003 Vamvakopoulos and Green; licensee BioMed Central Ltd. This is an Open Access article: verbatim copying and redistribution of this article are permitted in all media for any purpose, provided this notice is preserved along with the article's original URL.

\begin{abstract}
Background: Statins effectively lower blood cholesterol and the risk of cardiovascular death. Immunomodulatory actions, independent of their lipid-lowering effect, have also been ascribed to these compounds. Since macrophages participate in several vascular pathologies, we examined the effect of statin treatment on the survival and differentiation of primary human monocytes.
\end{abstract}

Methods: Peripheral blood mononuclear cells (PBMCs) from healthy individuals were cultured in the presence or absence of mevastatin. Apoptosis was monitored by annexin V / PI staining and flow cytometry. In parallel experiments, cultures were stimulated with LPS in the presence or absence of mevastatin and the release of IL-I $\beta$ and IL-IRa was measured by ELISA.

Results: Among PBMCs, mevastatin-treated monocytes were particularly susceptible to apoptosis, which occurred at doses $>1$ microM and was already maximal at 5 microM. However, even at the highest mevastatin dose used ( 10 microM), apoptosis occurred only after $24 \mathrm{~h}$ of culture, possibly reflecting a requirement for cell commitment to differentiation. After $72 \mathrm{~h}$ of treatment the vast majority $(>50 \%)$ of monocytes were undergoing apoptosis. Stimulation with LPS revealed that mevastatin-treated monocytes retained the high IL-I $\beta$ output characteristic of undifferentiated cells; conversely, IL-IRa release was inhibited. Concurrent treatment with mevalonolactone prevented the induction of apoptosis and suppressed both IL-I $\beta$ and IL-I Ra release in response to LPS, suggesting a rate-limiting role for HMG-CoA reductase in monocyte differentiation.

Conclusions: Our findings indicate that statins arrest the functional differentiation of monocytes into macrophages and steer these cells into apoptosis, suggesting a novel mechanism for the vasculoprotective properties of HMG-CoA reductase inhibitors.

\section{Background}

Advanced coronary artery disease (CAD) is currently a leading cause of morbidity and mortality in the western world and the most common indication for heart transplantation. Even after successful transplantation, allograft vasculopathy affects as many as $60 \%$ of cardiac grafts 
within one year [1] and is the principal cause of late graft loss. While their natural histories differ, CAD and allograft vasculopathy share certain features of their pathogenesis and histopathology. Prominent among these features is the recruitment and retention of peripheral blood monocytes in the vascular wall, an event that is thought to trigger the formation of vascular lesions.

Monocyte-derived macrophages play a central role in the pathogenesis of both native atherosclerosis and allograft vasculopathy $[2,3]$. Macrophages are an integral cellular component of the atherosclerotic plaque where they function to sequester lipids, giving rise to "foam cells". The release of extracellular matrix-degrading proteases by these cells, combined with their pro-apoptotic effect on adjacent vascular smooth muscle cells [4], are thought to destabilise the plaque, progressively leading to rupture. Furthermore, atherosclerotic plaque macrophages promote local coagulation by releasing prothrombotic mediators such as tissue factor. Similarly, though their precise role remains poorly defined, macrophages abound in the neointimal lesions associated with allograft vasculopathy and formation of these lesions is defective in macrophagedeficient mice [3]. Moreover, treatments that have proven effective in reducing neointimal lesion formation also reduced the macrophage burden of the lesion $[5,6]$. It seems likely, therefore, that macrophage turnover in the vascular wall may influence the rate of progression of both native atherosclerosis and allograft vasculopathy.

Statins are highly efficacious in controlling hyperlipidaemia and reducing the risk of acute coronary events and cardiovascular death [7]. The biological activity of statins stems from their chemical structure, which resembles that of mevalonic acid. Statins suppress de novo cholesterol biosynthesis by inhibiting HMG-CoA reductase, the ratelimiting enzyme of the mevalonate pathway [8]. Amazingly, statin therapy is well tolerated with few major adverse effects, usually attributable to metabolic interactions with other drugs [9].

Early animal studies suggested that, in addition to its antiatherosclerotic effect, statin treatment might also attenuate the development of allograft vasculopathy $[10,11]$. The first evidence for an association of post-transplant statin treatment with reduced incidence and progression of allograft vasculopathy in human cardiac allograft recipients came from a prospective study by Kobashigawa et al [12]. This finding was subsequently corroborated by others [13] and spurred interest in characterising the vasculoprotective effects of statins $[14,15]$.

Statins are now known to have multiple effects on native cellular components of the vascular wall as well as on monocytes / macrophages [16]. Given the involvement of macrophages in $\mathrm{CAD}$ and allograft vasculopathy, one plausible mechanism through which statins exert their vasculoprotective actions could be the induction of macrophage apoptosis. When grown in vitro monocytes differentiate into macrophages, a phenotypic transition heralded by down-regulation of the IL- $1 \beta$ response to lipopolysaccharide (LPS) $[17,18]$. Using this simple model, we explored the hypothesis that mevastatin treatment arrests monocyte-to-macrophage differentiation and, instead, steers these cells into apoptosis.

\section{Methods}

All aqueous solutions were prepared using endotoxin-free water from a MilliQ Biocel purification unit (Millipore, Bedford MA) and filter-sterilised. Reagents were obtained from Sigma (St Louis MO) unless otherwise indicated.

\section{Subjects and materials}

Peripheral blood mononuclear cells (PBMCs) obtained by venipuncture from six individuals were used in this study. All subjects were healthy volunteers recruited using procedures and documentation approved by the Cambridge Local Ethics Committee.

Mevastatin was reconstituted to $4 \mathrm{mM}$ in dimethyl sulfoxide (DMSO), stored at $4{ }^{\circ} \mathrm{C}$ in the dark and added to cell cultures at a final concentration of $10 \mu \mathrm{M}$. Mevalonolactone (ICN Biochemicals, Cleveland $\mathrm{OH}$ ), a membranepermeable internal ester of mevalonate that is hydrolysed by cytoplasmic esterases, was reconstituted to $40 \mathrm{mM}$ in DMSO, stored at $4{ }^{\circ} \mathrm{C}$ in the dark and used at a final concentration of $100 \mu \mathrm{M}$. Lipopolysaccharide (LPS; from E coli strain 055:B5) was dissolved in phosphate-buffered saline (PBS) and used at $5 \mu \mathrm{g} / \mathrm{mL}$ final concentration. Recombinant human gamma-interferon ( $\gamma$ IFN; Peprotech, London UK) was reconstituted in PBS and used at 50 $\mathrm{ng} / \mathrm{mL}(1000 \mathrm{U} / \mathrm{mL})$ final concentration.

\section{PBMC purification and handling}

Blood was processed immediately after phlebotomy. PBMCs were purified by centrifugation over Percoll (AP Biotech, Piscataway NJ), spin-washed once with cold modified Hanks' Balanced Salt Solution (containing 5 $\mathrm{mM} \mathrm{Na}_{4}$ EDTA, $1 \%$ BSA) and once with cold PBS at $250 \times$ $\mathrm{g}$ for $5 \mathrm{~min}$, resuspended in PBS and counted. The monocytic (CD33+hi) content of the PBMC population and the extent of neutrophil contamination were quantified by immunofluorescent staining of $5 \times 10^{5}$ cells with an antihuman CD33-FITC MAb (clone WM53; Serotec, Oxford UK) and analysis by flow cytometry. All PBMC preparations used in this study were essentially neutrophil-free (neutrophil content $<0.5 \%$ ).

The remaining PBMCs were resuspended in RPMI 1640 medium and recounted. Aliquots of this suspension, 
calculated to contain $2.5 \times 10^{5} \mathrm{CD} 33^{+}$hi cells each, were seeded in individual wells of a 24 -well tissue culture plate. Each well contained $1 \mathrm{~mL}$ of pre-warmed complete growth medium (RPMI 1640 supplemented with $10 \%$ FCS, $2 \mathrm{mM}$ L-glutamine, $50 \mathrm{U} / \mathrm{mL}$ penicillin and $50 \mu \mathrm{g} /$ $\mathrm{mL}$ streptomycin). Cell culture was performed at $37^{\circ} \mathrm{C} /$ $5 \% \mathrm{CO}_{2}$ in a humidified incubator.

\section{Analysis of apoptotic monocytes}

Apoptotic cells were identified by double supravital staining with recombinant FITC-conjugated annexin $\mathrm{V}$ and propidium iodide (PI) [19], using the TACS Apoptosis Detection kit (R\&D Systems, Minneapolis MN) according to the manufacturer's instructions. All cultures were performed and assayed in triplicate. Flow cytometric analysis was performed immediately after supravital staining. For each sample, 2,500 events were obtained in the monocyte region and gated onto a fluorescence dot plot, where the fraction of total annexin V-positive cells was determined. Common settings for forward / side scatter, fluorescence gains, colour compensation and fluorescence threshold were used throughout the study. These were determined by assaying unstained and single-stained cells (with PI or annexin $\mathrm{V}$ alone).

\section{Measurement of cytokine release}

The concentrations of IL-1 $\beta$ and IL-1Ra in cell culture supernatants were determined by ELISA using human Cytoset $^{\mathrm{TM}}$ kits (BioSource, Camarillo CA) according to the manufacturer's instructions. Cell culture supernatants were depleted of residual cells and cell debris by centrifugation, collected in microtubes and stored at $-20^{\circ} \mathrm{C}$ prior to the assay. Each supernatant was thawed once and both cytokines were assayed in parallel. All standards, samples and controls were assayed in duplicate.

\section{Statistical analysis}

Data were compiled and analysed using MicroSoft Excel ${ }^{\mathrm{TM}}$ (MicroSoft, Redmont WA). Descriptive statistics (mean; standard deviation; standard error of mean) were calculated for each treatment group. For both the apoptosis and cytokine release studies, group means were compared using the appropriate version of Student's unpaired t-test, as determined by the F-test for equality of variances. Test results are reported as two-tailed $\mathrm{p}$ values, where $\mathrm{p}<0.05$ was considered statistically significant. Summary data are reported as mean +/- SEM.

\section{Results}

Mevastatin-treated differentiating human monocytes undergo delayed apoptosis

Prolonged mevastatin treatment was associated with massive apoptosis of cultured human peripheral blood monocytes, but not lymphocytes (figure 1). Incubation with mevastatin for $24 \mathrm{~h}$ did not compromise monocyte viabil- ity when compared to untreated or vehicle-treated cell cultures. However, a 48 -h treatment with mevastatin resulted in the appearance of a large apoptotic monocyte population, as defined by light scatter criteria (granular cells of diminishing size) and annexin V-positive staining. At this time-point, $27.5+/-1.8 \%$ of mevastatin-treated monocytes were undergoing apoptosis compared with $8.8+$ /$1.6 \%$ of vehicle-treated monocytes ( $\mathrm{p}=0.001$; figure 2$)$.

Monocyte viability was severely compromised after $72 \mathrm{~h}$ of mevastatin treatment, when $53.0+/-3.9 \%$ of monocytes were undergoing apoptosis compared to $12.9+/$ $1.3 \%$ of vehicle-treated monocytes $(\mathrm{p}=0.0006$; figure 2$)$. Dose-response experiments showed that mevastatin triggered apoptosis at concentrations $>1 \mu \mathrm{M}\left(\mathrm{EC}_{50} \sim 2.5 \mu \mathrm{M}\right.$ at $72 \mathrm{~h}$; data not shown) and that this effect was already maximal at $5 \mu \mathrm{M}$. Consistent with 48 -h time-point observations, flow cytometric analysis revealed relatively few annexin $\mathrm{V}$ single-positive monocytes $(<18 \%$ of apoptotic population), indicating rapid progression to apoptosis. In contrast to the lymphocyte population, the size of which did not vary significantly over time, viable monocyte numbers had plummeted after $72 \mathrm{~h}$ of treatment with mevastatin (figure 1C).

Supplementation of mevastatin-treated cultures with mevalonolactone attenuated monocyte apoptosis by $83.1 \%$ (range $72.6-99.3 \% ; \mathrm{p}=0.01$ ) and $77.4 \%$ (range $56.4-90.9 \% ; \mathrm{p}=0.01$ ) at $48 \mathrm{~h}$ and $72 \mathrm{~h}$, respectively (figure 2).

\section{Mevastatin treatment arrests monocyte differentiation in vitro}

Interleukin- $1 \beta$ release after LPS stimulation is suppressed early during monocyte-to-macrophage differentiation in vitro and in vivo. Continuous mevastatin treatment of nonstimulated human PBMCs for $48 \mathrm{~h}$ did not affect constitutive IL-1 $\beta$ output $(47.7+/-13.6$ vs $45.1+/-9.0 \mathrm{pg} / \mathrm{mL}$ in vehicle-treated cultures). However, when LPS was added at $24 \mathrm{~h}$ mevastatin-treated cells released approximately 40 -fold more IL- $1 \beta$ compared to vehicle-treated cells $(15,559.1+/-5,518$ vs $389.2+/-163 \mathrm{pg} / \mathrm{mL} ; \mathrm{p}=0.05)$, a level comparable to that obtained with freshly harvested, undifferentiated monocytes (figure 3A).

Gamma-interferon is known to potentiate induction of IL-1 $\beta$ by LPS [20]. In this study, incubation of vehicletreated monocytes with $\gamma$ IFN for $6 \mathrm{~h}$ prior to addition of LPS increased IL- $1 \beta$ output approximately 4 -fold. Under the same conditions, mevastatin-treated monocytes released approximately 11 -fold more IL- $1 \beta$ than vehicletreated cells $(18,423.4+/-4,152$ vs 1,649.7+/- $338.4 \mathrm{pg} /$ $\mathrm{mL} ; \mathrm{p}=0.03$ ), although the enhancing effect of $\gamma \mathrm{IFN}$ was no longer apparent. 

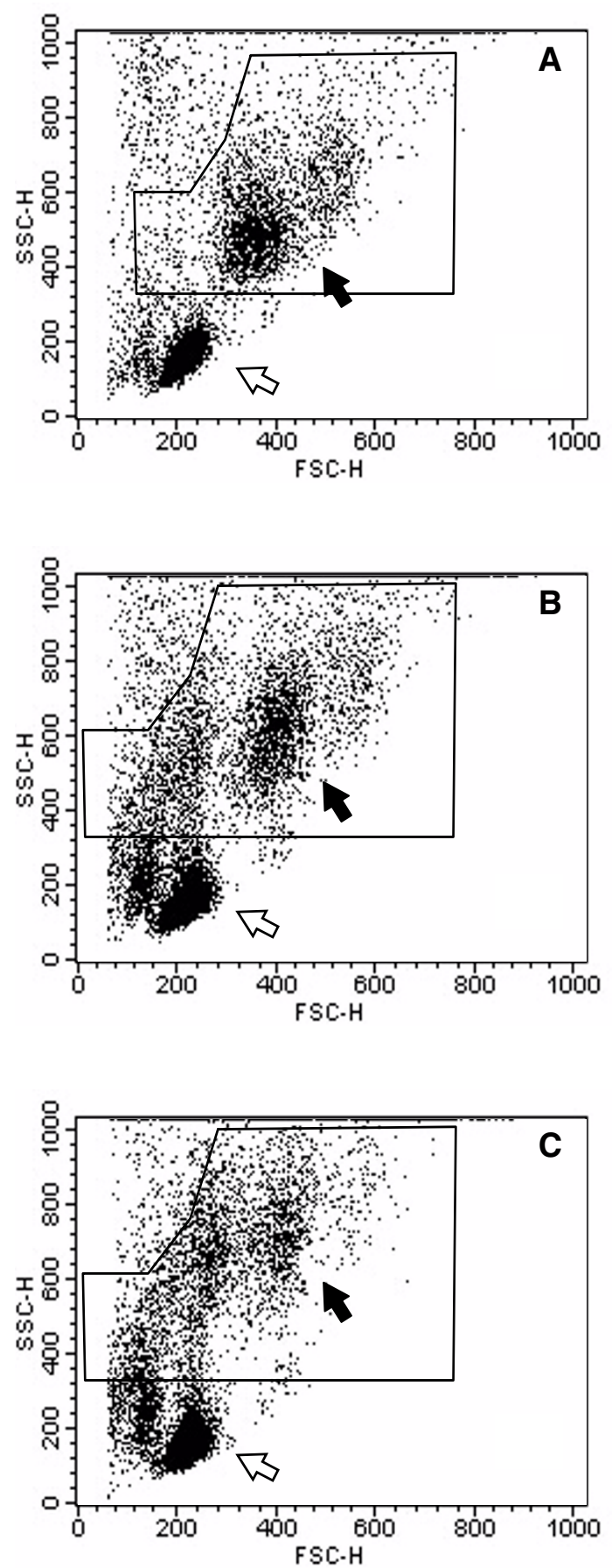

\section{Figure I}

Mevastatin-treated differentiating monocytes are particularly susceptible to apoptosis. After $24 \mathrm{~h}$ of statin treatment monocytes still constituted a single, viable cell population (panel A, black arrow). By $48 \mathrm{~h}$ this viable monocytic population had decreased in size and a second population of smaller, annexin $\mathrm{V}$-positive cells had appeared (B). By $72 \mathrm{~h}$ the majority of monocytes were undergoing apoptosis (C). Conversely, peripheral blood lymphocytes (white arrow) remained largely viable throughout the observation period. Results shown here are representative of 18 experiments (three per individual). 


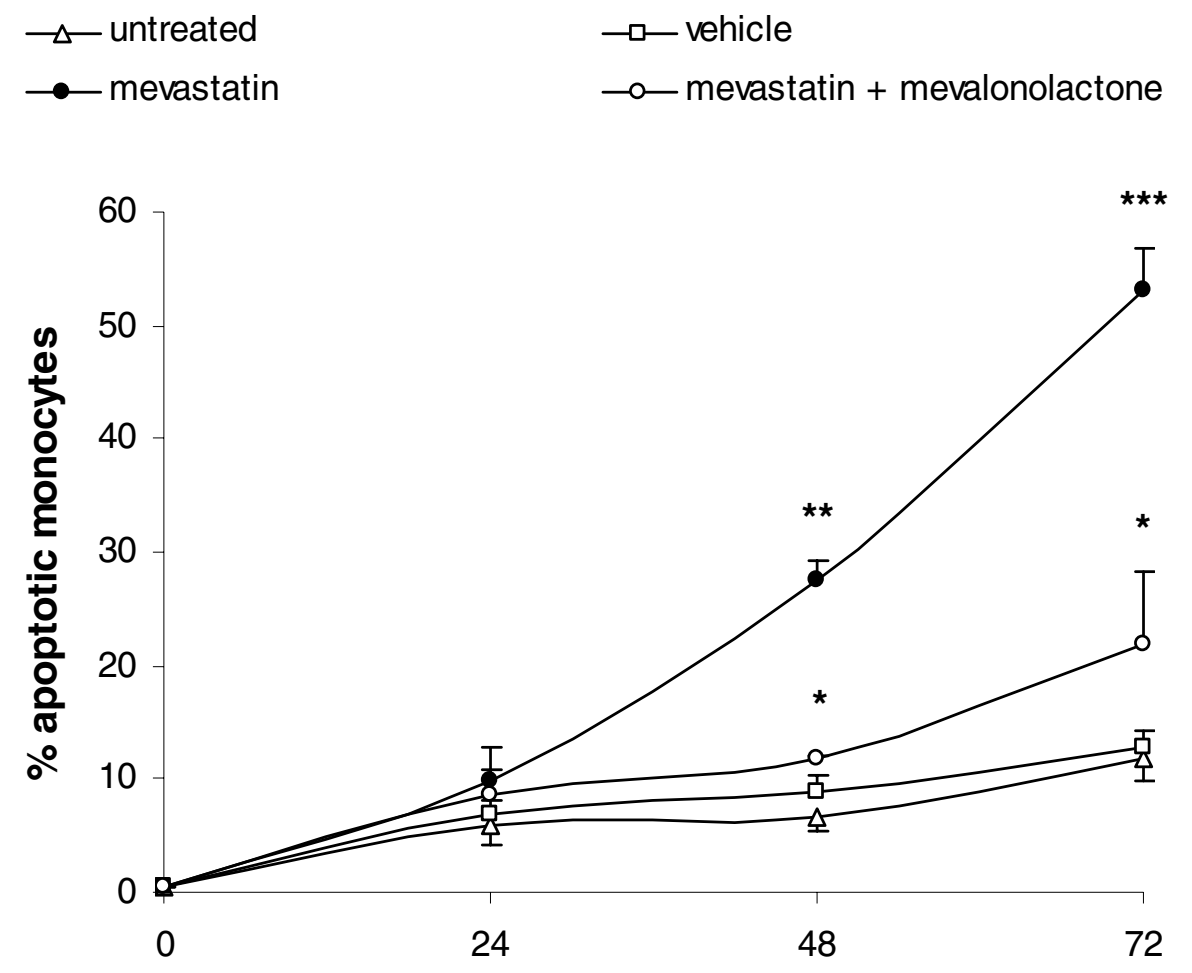

\section{treatment duration (h)}

Figure 2

Kinetics of apoptosis in mevastatin-treated human peripheral blood monocytes. Cultures were treated with vehicle $(0.25 \%$ DMSO); $10 \mu \mathrm{M}$ mevastatin; or mevastatin plus $100 \mu \mathrm{M}$ mevalonolactone. Error bars represent SEM. *, $\mathrm{P}<0.05$; **, $\mathrm{P}<0.0 \mathrm{I}$; $* * *, \mathrm{p}<0.001$.

Inclusion of mevalonolactone in the growth medium completely prevented the mevastatin-induced blockade of monocyte differentiation, both in the presence and in the absence of $\gamma \mathrm{IFN}$ ( $\mathrm{p}=0.02$ and 0.05 , respectively; figure $3 \mathrm{~A})$. In fact, mevalonolactone supplementation further suppressed IL-1 $\beta$ release below that of vehicle-treated monocytes. When LPS was used alone, mevalonolactonetreated monocytes released $62 \%$ less IL- $1 \beta$ than vehicletreated cells $(147.7+/-38.3$ vs $389.2+/-163.0 \mathrm{pg} / \mathrm{mL} ; \mathrm{p}=$ 0.25). When LPS was used in combination with $\gamma \mathrm{IFN}$, mevalonolactone suppressed IL- $1 \beta$ release by $81.5 \%$, compared to vehicle treatment (305.2 +/- 65.3 vs 1,649.7 +/- $338.4 \mathrm{pg} / \mathrm{mL} ; \mathrm{p}=0.03$ ).

\section{Mevastatin suppresses LPS-induced IL-IRa release from differentiating monocytes}

The interleukin-1 receptor antagonist is an important endogenous regulator of IL-1. IL-1Ra inducibility by LPS is also progressively down-regulated during monocyte-tomacrophage differentiation [21]. In contrast to our observations with IL- $1 \beta$, mevastatin treatment of non-stimulated PBMCs down-regulated constitutive IL-1Ra output at $48 \mathrm{~h}$ by approximately $40 \%(\mathrm{p}=0.24$; figure $3 \mathrm{~B})$; interestingly, the magnitude of this reduction is similar to the rate of monocyte apoptosis seen at that same time-point. Following LPS stimulation, mevastatin-treated monocytes again released less IL-1Ra than vehicle-treated cells ( $\mathrm{p}=$ 0.29 ). This consistent observation reached statistical significance after combined $\gamma$ IFN / LPS stimulation, when mevastatin-treated monocytes released approximately 
qundiff control $\square$ vehicle $\mathbf{m}$ mevastatin $\square$ mevastatin + mevalonolactone

A

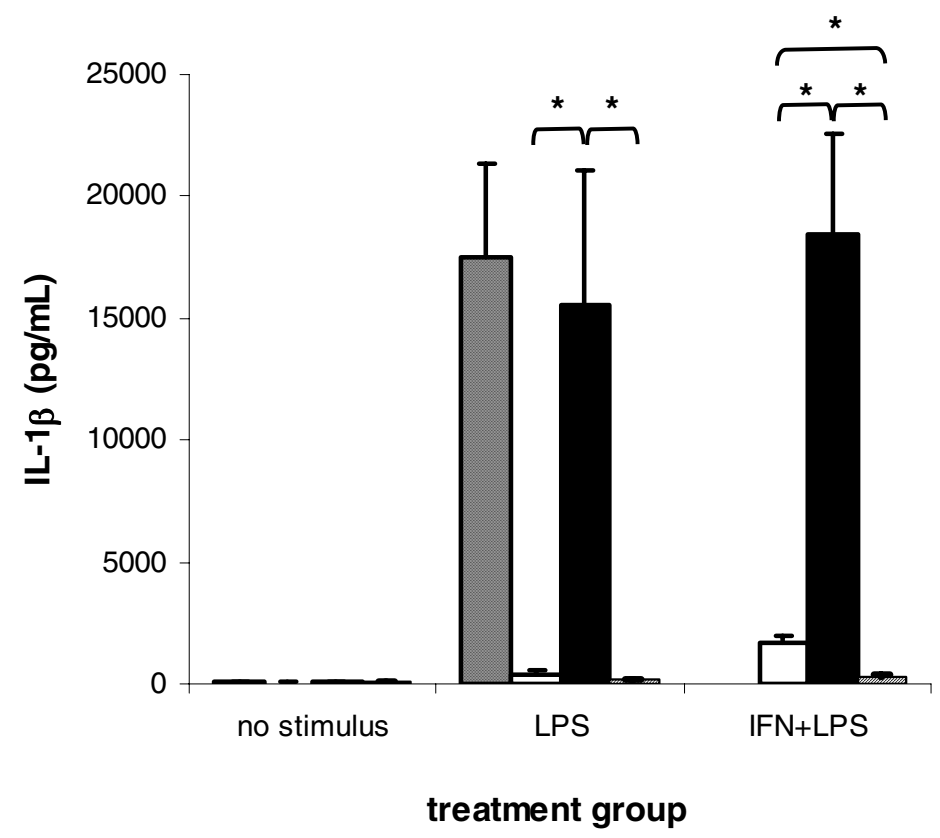

$\square$ undiff control $\square$ vehicle $\boldsymbol{\square}$ mevastatin $\boldsymbol{\square}$ mevastatin + mevalonolactone

B

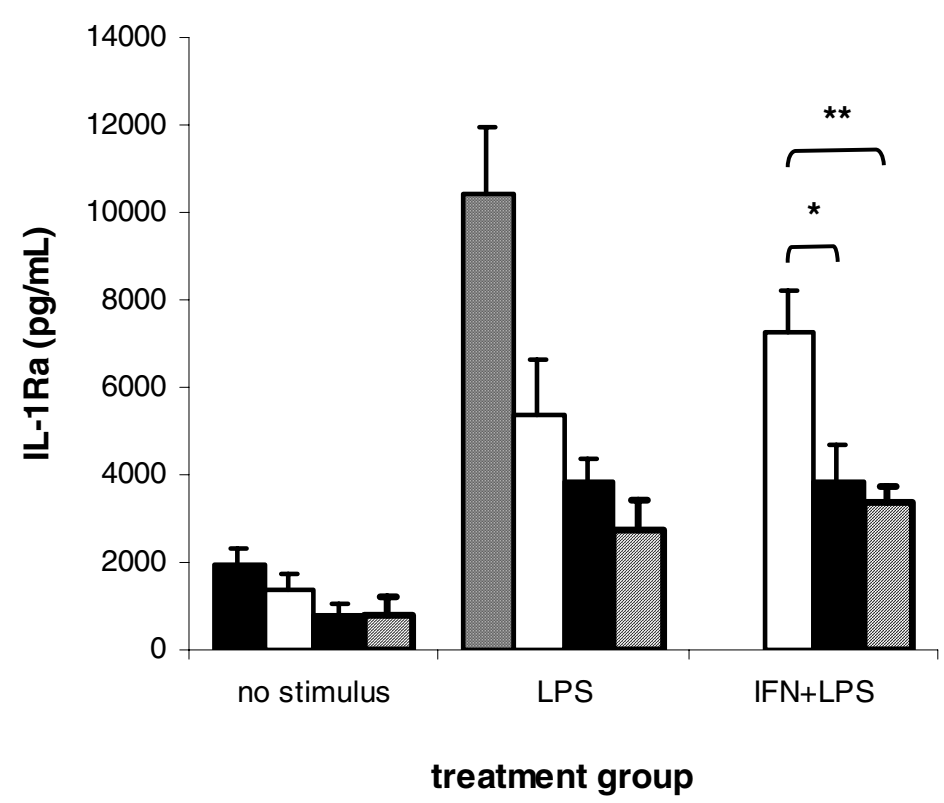

\section{Figure 3}

Mevastatin arrests the functional maturation of cultured human peripheral blood monocytes. LPS was added to PBMC cultures either at the onset (undifferentiated control), or after $24 \mathrm{~h}$, of cell culture and supernatants were harvested $24 \mathrm{~h}$ later in each case. Pre-treatment with $\gamma$ IFN was only applicable to differentiating cells. Mevastatin treatment preserved monocyte responsiveness to LPS in terms of IL-I $\beta$ release (A) but suppressed IL-IRa release (B). *, $\mathrm{P}<0.05$; **, $\mathrm{P}<0.0$ I (brackets indicate groups being compared). 
$50 \%$ less IL-1Ra than vehicle-treated cells $(3,836.2+/$ 841.6 vs $7,286.9+/-928.8 \mathrm{pg} / \mathrm{mL} ; \mathrm{p}=0.03)$. Crucially, mevalonolactone apparently failed to prevent the suppression of IL-1Ra release by mevastatin (figure 3B).

\section{Discussion}

Fibroproliferative vascular disease, thought to arise as a result of endothelial stress or trauma, is characterised by a complex pathology that culminates in a spectrum of manifestations, depending on the nature of the triggering event. Thus, native atherosclerosis is thought to occur mainly as a result of chronic oxidative stress, while mechanical endothelial trauma initiates restenosis after angioplasty or stenting. Lastly, allograft vasculopathy is thought to arise chiefly as a result of endothelial dysfunction precipitated by both immune and non-immune injury. Monocyte recruitment and retention in the vascular wall is a unifying feature of these diverse outcomes and correlates strongly with the timing and severity of vascular lesion formation [22-25].

Peripheral blood monocytes represent a heterogeneous population of immature cells that differentiate upon exiting the circulation. The tissue microenvironment plays a crucial role in initiating and guiding monocyte differentiation: arrest on a solid matrix is generally sufficient to initiate this process, while the presence of particular cytokines and growth factors functions to steer it towards a variety of phenotypes [26-28]. This process can be faithfully reproduced in vitro where, in the absence of exogenous growth factors, approximately $80 \%$ of peripheral blood monocytes spontaneously develop into macrophages [29]. One of the earliest functional indices of monocyte-to-macrophage differentiation, both in vitro and in vivo, is a markedly attenuated IL-1 $\beta$ release in response to LPS $[17,18]$.

Here we have demonstrated that mevastatin, an inhibitor of HMG-CoA reductase, abolishes the profound downregulation of IL- $1 \beta$ release associated with monocyte differentiation; and that this effect coincides temporally with the induction of monocyte-specific apoptosis in human PBMC cultures. While monocyte differentiation proceeds spontaneously in vitro, lymphocytes differentiate only in response to signals via the $\mathrm{T} / \mathrm{B}$ cell receptor complexes, which are lacking in pure PBMC cultures from single individuals; notably, these cells remained viable throughout the observation period. Therefore, unlike previous observations with murine J744 myeloid cells [30], the susceptibility of primary monocytes to statin-induced apoptosis appears to be tightly linked to the process of cell differentiation.

The precise molecular mechanisms underlying these findings are currently under investigation; depletion of down- stream products of the mevalonate pathway such as the phosphorylated geranylgeranyl and farnesyl isoprenoids, which would compromise G-protein function, is likely to be involved. Shortage of such intermediates may be exacerbated in the face of increased utilization of the mevalonate pathway that occurs during monocyte differentiation [31], explaining the failure of mevalonolactone supplementation to completely prevent apoptosis in our experimental set-up. Conversely, mevalonolactone appeared to accelerate the suppression of LPS-induced IL$1 \beta$ release in differentiating monocytes, hinting that the mevalonate pathway regulates this process both dynamically and bi-directionally. Hence this metabolic pathway may represent a promising therapeutic target for diseases involving dysregulated macrophage function.

Monocyte turnover in solid tissue is determined by the balance between recruitment and clearance. Overproduction of monocyte chemoattractant protein (MCP-1) by native vascular cells and macrophages is a major mechanism promoting macrophage accumulation in atherosclerotic [32,33] and neointimal [34,35] lesions. Statin treatment was recently shown to down-regulate MCP-1 production in vitro and in vivo [36]; and to suppress the release of various other atherothrombotic mediators by plaque macrophages [15,36-40]. However, in most cases, the potential contribution of cell death to these findings was not concurrently investigated. Here we show that HMG-CoA reductase inhibition suppressed the release of IL-1Ra from LPS-stimulated monocytes; but that this suppression was largely accounted for by apoptotic cell death. Unlike IL-1 $\beta$, the release of which occurs via stimulation of the $\mathrm{P}_{2} \mathrm{X}_{7}$ receptor at the level of the cell surface [41] and is thus refractory to apoptosis, secretion of IL-1Ra follows the classical pathway, which is effectively shut down during apoptosis [42]. While suppression of endothelial MCP-1 synthesis might genuinely contribute to the benefits of statin therapy, we suggest that induction of monocyte apoptosis may underlie many downstream statin actions, including the reduction in plaque macrophage counts and inhibition of in situ MMP and TF production [37-40] (figure 4). It is noteworthy that, since osteoclasts are also developmentally derived from peripheral blood monocytes, this hypothesis fits well with the recently proposed role of statins as modulators of bone formation [43].

Interestingly, in vivo studies so far do not lend support to our hypothesis. Libby and colleagues have postulated that foam cell apoptosis might perpetuate vascular lipid accumulation, contributing to atherosclerotic plaque growth [2]. Furthermore, in a recent, very elegant study these authors concluded that apoptosis is not involved in the reduction of plaque macrophage counts by cerivastatin and, instead, attributed these effects to suppression of cell 


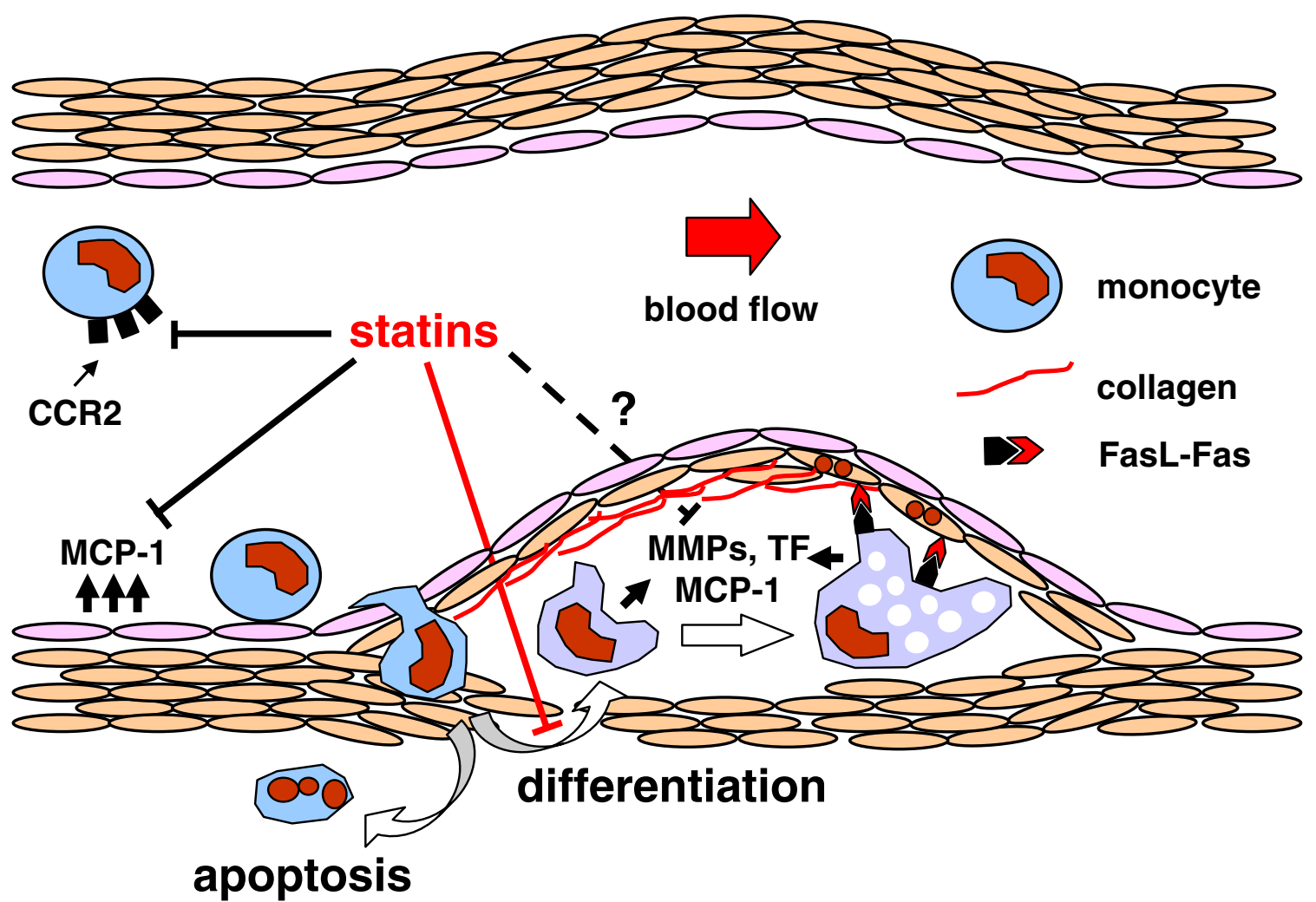

\section{Figure 4}

Statin-mediated monocyte apoptosis in the context of atherosclerosis. During formation of the atherosclerotic plaque monocytes are recruited and retained in the vascular wall, where they differentiate into macrophages. Macrophages incorporate lipids giving rise to foam cells, which exhibit a dysregulated phenotype possibly due to oxidative stress. Mature macrophages and foam cells are thought to promote plaque rupture by eroding the fibromuscular cap. This is likely achieved through release of matrix-degrading proteases and also via FasL-mediated cytotoxic effects on adjacent vascular smooth muscle cells. Statins modulate both primary vascular release of MCP-I and monocyte chemotaxis. In situ monocyte apoptosis might also contribute to their downstream effects on plaque stability.

growth [38]. The data presented here clearly challenge this conclusion and we feel that rejecting apoptosis as a possible mechanism of statin vasculoprotection may be premature on several counts. Firstly, it is well known that apoptotic cells are rapidly cleared in vivo and, in their paper, Aikawa and colleagues acknowledged that very few apoptotic cells were actually observed in both the control and statin-treated groups [38]. In view of this, it is unfortunate that these authors did not assess the role of apoptosis in their in vitro studies of monocyte differentiation. Moreover, several reports have cautioned that the TUNEL assay, used by Aikawa et al, may not allow accurate quantification of apoptotic cells $[44,45]$. It might be argued that cerivastatin doses investigated in the aforementioned study $(0.01-0.05 \mu \mathrm{M})$ reflect therapeutic plasma levels of that drug, which may not be pro-apoptotic. However, in support of our own findings, a recent study by Kaneider et al [46] showed significant monocyte pro-apoptotic activity of low-dose $(0.01 \mu \mathrm{M})$ cerivastatin, in terms of caspase3 activation. It should be noted that cerivastatin is relatively hydrophilic and a more potent inhibitor of HMGCoA reductase than mevastatin; thus our findings with mevastatin at relatively high doses may still be therapeutically relevant. Further in vitro studies with clinically used statins are currently in progress to address this issue. 


\section{Conclusions}

HMG-CoA reductase inhibition in human peripheral blood monocytes appears to maintain them in a functionally immature state and to render them susceptible to apoptosis. We suggest that this may represent one mechanism whereby statins decrease macrophage load and the release of prothrombotic mediators in vascular lesions, potentially leading to their prevention or regression.

\section{Competing interests}

None declared.

\section{Authors' contributions}

JEV conceived and led the design of this study; carried out all experimental work and statistical analysis; and drafted the manuscript. CG participated in the design of this study, supervised its conduct and secured funding. Both authors read and approved the final manuscript.

\section{Acknowledgements}

This work was funded by the Northwick Park Institute for Medical Research (NPIMR) and the Papworth Hospital NHS Trust Fund. JV is a CIMO scholar-in-residence (Finnish Ministry of Education) whose work is also supported by grants from the Institute of Biomedical Science (UK).

\section{References}

I. Julius BK, Attenhofer Jost $\mathrm{CH}$, Sutsch G, Brunner HP, Kuenzli A, Vogt PR, Turina M, Hess OM and Kiowski W: Incidence, progression and functional significance of cardiac allograft vasculopathy after heart transplantation Transplantation 2000, 69:847-853.

2. Libby P, Geng YJ, Aikawa M, Schoenbeck U, Mach F, Clinton SK, Sukhova GK and Lee RT: Macrophages and atherosclerotic plaque stability Curr Opin Lipidol 1996, 7:330-335.

3. Shi C, Lee W-S, He Q, Zhang D, Fletcher DL Jr, Newell JB and Haber $\mathrm{E}$ : Immunologic basis of transplant-associated arteriosclerosis Proc Natl Acad Sci USA 1996, 93:4051-4056.

4. Boyle JJ, Bowyer DE, Weissberg PL and Bennett MR: Human bloodderived macrophages induce apoptosis in human plaquederived vascular smooth muscle cells by Fas-ligand I Fas interactions Arterioscler Thromb Vasc Biol 200 I, 2 I : I $402-1407$.

5. Azuma $H$, Nadeau KC, Ishibashi M and Tilney NL: Prevention of functional, structural and molecular changes of chronic rejection of rat renal allografts by a specific macrophage inhibitor Transplantation 1995, 60:1577-1582.

6. Niebauer J, Schwarzacher SP, Hayase M, Wang B, Kernoff RS, Cooke $\mathrm{J}$ and Yeung AC: Local L-arginine delivery after baloon angioplasty reduces monocyte binding and induces apoptosis Circulation 1999, 100:1830-1835.

7. Rosenson RS and Tangney CC: Antiatherothrombotic properties of statins: implications for cardiovascular event reduction J Am Med Assoc 1998, 279: 1643-1650.

8. Endo A, Kuroda $M$ and Tanzawa $K$ : Competitive inhibition of 3hydroxy-3-methylglutaryl coenzyme $A$ reductase by ML236A and ML-236B fungal metabolites, having hypocholesterolemic activity FEBS Lett 1976, 72:323-326.

9. Christians U, Jacobsen W and Floren LC: Metabolism and drug interactions of 3-hydroxy-3-methylglutaryl coenzyme A reductase inhibitors in transplant patients: are the statins mechanistically similar? Pharmacol Ther 1998, 80: I-34.

10. Meiser BM, Wenke K, Thiery J, Wolf S, Devens C, Seidel D, Hammer C, Billingham ME and Reichart B: Simvastatin decreases accelerated graft vessel disease after heart transplantation in an animal model Transplant Proc 1993, 25:2077-2079.

II. Maggard MA, Ke B, Wang T, Kaldas F, Seu P, Busuttil RW and Imagawa DK: Effects of pravastatin on chronic rejection of rat cardiac allografts Transplantation 1998, 65:|49-I55.
12. Kobashigawa JA, Katznelson S, Laks H, Johnson JA, Yeatman L, Wang $X M$, Chia D, Terasaki PI, Sabad A, Cogert GA, Trosian K, Hamilton MA, Hage A, Drinkwater D and Stevenson LW: Effect of pravastatin on outcomes after cardiac transplantation $N$ Engl J Med 1995, 333:621-627.

13. Wenke K, Meiser B, Thiery J, Nagel D, von Scheidt W, Steinbeck G, Seidel D and Reichart B: Simvastatin reduces graft vessel disease and mortality after heart transplantation: a four-year randomized trial Circulation 1997, 96:1398-|402.

14. Katznelson $S$ and Kobashigawa JA: Dual roles of HMG-CoA reductase inhibitors in solid organ transplantation: lipid lowering and immunosuppression Kidney Intl I 995, 48:SI I2-SI I 5.

15. Diomede L, Albani D, Sottocorno M, Donati MB, Bianchi M, Fruscella $P$ and Salmona $M$ : In vivo anti-inflammatory effect of statins is mediated by nonsterol mevalonate products Arterioscler Thromb Vasc Biol 2001, 2 I : I327- 1332.

16. Koh KK: Effects of statins on vascular wall: vasomotor function, inflammation, and plaque stability Cardiovasc Res 2000, 47:648-657.

17. Elias JA, Schreiber AD, Gustilo K, Chien P, Rossman MD, Lammie PJ and Daniele RP: Differential interleukin-I elaboration by unfractionated and density fractionated human alveolar macrophages and blood monocytes: relationship to cell maturity J Immunol 1985, I 35:31 98-3204.

18. Burchett SK, Weaver WM, Westall JA, Larsen A, Kronheim S and Wilson CB: Regulation of tumor necrosis factor / cachectin and IL-I secretion in human mononuclear phagocytes J Immunol 1988, | 40:3473-348I.

19. Vermes I, Haanen C, Steffens-Nakken $\mathrm{H}$ and Reutelingsperger C: A novel assay for apoptosis: flow cytometric detection of phosphatidylserine expression on early apoptotic cells using fluorescein-labelled annexin V J Immunol Meth 1995, I 84:39-5I.

20. Newton RC: Effect of interferon on the induction of human monocyte secretion of interleukin- I activity Immunology I985, 56:44I-446.

2I. Vamvakopoulos JE, Green C and Metcalfe S: Genetic control of ILI $\beta$ bioactivity through differential regulation of the IL-I receptor antagonist Eur J Immunol 2002, 32:2988-2996.

22. Moreno PR, Bernardi VH, Lopez-Cuellar J, Newell JB, McMellon C, Gold HK, Palacios IF, Fuster V and Fallon JT: Macrophage infiltration predicts restenosis after coronary intervention in patients with unstable angina Circulation 1996, 94:3098-3102.

23. Kim C-J, Khoo JC, Gillotte-Taylor K, Li A, Palinski W, Glass CK and Steinberg D: Polymerase chain reaction-based method for quantifying recruitment of monocytes to mouse atherosclerotic lesions in vivo : enhancement by tumor necrosis factoralpha and interleukin-Ibeta Atheroscler Thromb Vasc Biol 2000, 20:1976-1982.

24. Kitagawa-Sakakida S, Tori M, Li Z, Horiguchi K, Izutani H, Matsuda H and Shirakura $R$ : Active cell migration in retransplanted rat cardiac allografts during the course of chronic rejection J Heart Lung Transplant 2000, 19:584-590.

25. Lehr H-A, Sagban TA, Ihling C, Zähringer U, Hungerer KD, Blumrich $M$, Reifenberg $K$ and Bhakdi S: Immunopathogenesis of atherosclerosis: endotoxin accelerates atherosclerosis in rabbits on hypercholesterolemic diet Circulation 2001, 104:914-920.

26. Chomarat P, Banchereau J, Davoust J and Palucka AK: IL-6 switches the differentiation of monocytes from dendritic cells to macrophages Nat Immunol 2000, I:5 I0-5I4.

27. Abe R, Donnelly SC, Peng T, Bucala R and Metz CN: Peripheral blood fibrocytes: differentiation pathway and migration to wound sites J Immunol 200I, I 66:7556-7562.

28. Mohamadzadeh M, Berard F, Essert G, Chalouni C, Pulendran B, Davoust J, Bridges G, Palucka AK and Banchereau J: Interleukin 15 skews monocyte differentiation into dendritic cells with features of Langerhans cells J Exp Med 2001, 194:1013-1020.

29. Grage-Griebenow E, Flad H-D and Ernst M: Heterogeneity of human peripheral blood monocyte subsets J Leukoc Biol 2001 , 69:11-20.

30. Coxon FP, Benford HL, Russell GG and Rogers MJ: Protein synthesis is required for caspase activation and induction of apoptosis by bisphosphonate drugs Mol Pharmacol 1998, 54:63 |-638.

31. Knight BL, Patel DD and Soutar AK: The regulation of 3-hydroxy3-methylglutaryl-CoA reductase activity, cholesterol esterification and the expression of low-density lipoprotein recep- 
tors in cultured monocyte-derived macrophages Biochem J 1983, 21 0:523-532.

32. Nelken NA, Coughlin SR, Gordon D and Wilcox JN: Monocyte chemoattractant protein-I in human atheromatous plaques J Clin Invest 199I, 88: I I2I-I I27.

33. Boring L, Gosling J, Cleary M and Charo IF: Decreased lesion formation in CCR2-/- mice reveals a role for chemokines in the initiation of atherosclerosis Nature 1998, 394:894-897.

34. Furukawa Y, Matsumori A, Ohashi N, Shioi T, Ono K, Harada A, Matsushima $K$ and Sasayama S: Anti-monocyte chemoattractant protein-I / monocyte chemotactic and activating factor antibody inhibits neointimal hyperplasia in injured rat carotid arteries Circulation Res 1999, 84:306-314.

35. Gao W, Topham PS, King JA, Smiley ST, Csizmadia V, Lu B, Gerard C] and Hancock WW: Targeting of the chemokine receptor CCRI suppresses development of acute and chronic cardiac allograft rejection J Clin Invest 2000, 105:35-44.

36. Romano M, Diomede L, Sironi M, Massimiliano M, Sottocorno M Polentarutti N, Guglielmotti A, Albani D, Bruno A, Fruscella P, Salmona $M$, Vecchi A, Pinza M and Mantovani A: Inhibition of monocyte chemotactic protein-I synthesis by statins Lab lnvest 2000 , 80:1095-II00.

37. Bellosta $S$, Via D, Canavesi M, Pfister P, Fumagalli R, Paoletti R and Bernini F: HMG-CoA reductase inhibitors reduce MMP-9 secretion by macrophages Arterioscler Thromb Vasc Biol 1998, I 8: |67|-|678.

38. Aikawa M, Rabkin E, Sugiyama S, Voglic SJ, Fukumoto Y, Furukawa $Y$, Shiomi M, Schoen FJ and Libby P: An HMG-CoA reductase inhibitor, cerivastatin, suppresses growth of macrophages expressing matrix metalloproteinases and tissue factor in vivo and in vitro Circulation 200I, I03:276-283.

39. Fukumoto Y, Libby P, Rabkin E, Hill CC, Enomoto M, Hirouchi Y, Shiomi $M$ and Aikawa M: Statins alter smooth muscle cell accumulation and collagen content in established atheroma of watanabe heritable hyperlipidemic rabbits Circulation 200I, 103:993-999.

40. Baetta R, Camera M, Comparato C, Altana C, Ezekowitz MD and Tremoli E: Fluvastatin reduces tissue factor expression and macrophage accumulation in carotid lesions of cholesterolfed rabbits in the absence of lipid lowering Arterioscler Thromb Vasc Biol 2002, 22:692-698.

41. Mackenzie A, Wilson HL, Kiss-Toth E, Dower SK, North RA and Surprenant A: Rapid secretion of interleukin- I beta by microvesicle shedding Immunity 200 I, I 5:825-835.

42. Nozawa K, Casiano C, Hamel J, Molinaro C, Fritzler M and Chan E: Fragmentation of Golgi complex and Golgi autoantigens during apoptosis and necrosis Arthritis Res 2002, 4:R3.

43. Edwards CJ and Spector TD: Statins as modulators of bone formation Arthritis Res 2002, 4:15I-I53.

44. Del Bino G, Darzynkiewicz Z, Degraef C, Mosselmans R, Fokan D and Galand P: Comparison of methods based on annexin-V binding, DNA content or TUNEL for evaluating cell death in HL-60 and adherent MCF-7 cells Cell Prolif 1999, 32:25-37.

45. Leite M, Quinta-Costa M, Leite PS and Guimaraes JE: Critical evaluation of techniques to detect and measure cell death study in a model of UV radiation of the leukaemic cell line HL60 Anal Cell Pathol 1999, 19:139-I5I.

46. Kaneider NC, Reinisch CM, Dunzendorfer S, Meierhofer C, Djanani $A$ and Wiedermann C]: Induction of apoptosis and inhibition of migration of inflammatory and vascular wall cells by cerivastatin Atherosclerosis 200I, 158:23-33.

\section{Pre-publication history}

The pre-publication history for this paper can be accessed here:

http://www.biomedcentral.com/1471-2261/3/6/prepub
Publish with Biomed Central and every scientist can read your work free of charge

"BioMed Central will be the most significant development for disseminating the results of biomedical research in our lifetime. "

Sir Paul Nurse, Cancer Research UK

Your research papers will be:

- available free of charge to the entire biomedical community

- peer reviewed and published immediately upon acceptance

- cited in PubMed and archived on PubMed Central

- yours - you keep the copyright

Submit your manuscript here:

http://www.biomedcentral.com/info/publishing_adv.asp
BioMedcentral 